\title{
A system dynamics approach to logistics outsourcing policies and decisions
}

\author{
Raul Arellano Caldeira Franco ${ }^{\text {a* }}$, Hugo Tsugunobu Yoshida Yoshizaki ${ }^{b}$, José Geraldo Vidal Vieira ${ }^{\mathrm{c}}$ \\ aniversidade Estadual de Campinas, Campinas, SP, Brasil \\ bUniversidade de São Paulo, São Paulo, SP, Brasil \\ 'Universidade Federal de São Carlos, Sorocaba, SP, Brasil \\ *raul@arellano.com.br
}

\begin{abstract}
This paper is based on a revelatory single-case study that uses a system dynamics model to analyze the costs and policies of a distribution logistics outsourcing process (i.e., the warehousing and transportation activities) of a Brazilian consumer packaged goods (CPG) company. The model considers the costs before and after the outsourced operation startup and how these costs influence the net present value (NPV) of the process. The model's findings suggest policies, such as the reduction of the ex-ante period and the ex-ante reactive and proactive monitoring of operations, to obtain optimal financial results. In addition, the model provides guidelines for the contract lengths and demonstrates that in the outsourcing process, the greatest gains result during periods of low inflation and low interest rates in a stable economy.
\end{abstract}

Keywords

Outsourcing. Logistics. Decision-making. Inter-organizational relationships. Transaction costs.

\section{Introduction}

The logistics outsourcing decision-making process entails the selection of a third party logistics (3PL) provider. The activities performed in this process are highly complex because several functional areas must be involved and internal and external factors must be considered (Wanke, 2004). In addition, the timing of the processes, such as the evaluation, planning and implementation periods; the transaction costs (Williamson, 1985); and the switching costs (Klemperer, 1987) must be considered.

Normally, the outsourcing of logistics operations focuses on cost reduction (Lieb \& Kendrick, 2003; Maltz \& Ellram, 1997), which is increasingly shared among the outsourcing collaborative partners (Yoon $\&$ Nof, 2010). Operational costs must consider factors such as the relationship with external customers and the service levels, in addition to internal clients and products (Peck et al., 1999; Tsai et al., 2011). The focus on distribution to external clients implies obtaining 3PL performance data to monitor and increasing customer satisfaction.

Therefore, an evaluation of the total cost of contracting a 3PL provider for distribution must include the traditional logistics costs (Lambert \& Emmelhainz, 1999; Clark Junior \& Jones, 2008), transaction costs and the switching costs that occur prior to the start of the outsourced operations (ex-ante) and after the 3PL provider assumes control $(e x-p o s t)$. The transaction costs refer to the costs of, for instance, monitoring the service levels to the end customers (including the costs of hiring personnel to continuously monitor operations), of certification processes and of collecting information (Li \& Lin, 2006). According to Bragg (1998), the switching costs are related mainly to the problem of the ex-ante low morale of the contracting company employees and the learning of the processes by the new employees hired by the 3PL provider until operations stabilize. These factors generate costs that are not typically 
considered in an outsourcing process, including primarily the ex-ante costs, which occur prior to the outsourcing of operations.

Lambert \& Emmelhainz (1999) and McCray \& Clark Junior (1999) describe a tendency to focus the logistics outsourcing decision-making on the initial phases of identifying the need to outsource and evaluating and selecting the 3PL provider. lañez \& Cunha (2006) analyze the relevant attributes that should be considered in this decision-making process. Bandeira et al. (2012) analyze a logistics outsourcing failure in a telecommunications company and defend that the strategy of the organization should be aligned with the contracting model. The justification of this research is based on the phases of planning (ex-ante), implementation and stabilization of the outsourced operations (ex-post) and the related costs and policies that may improve the logistics outsourcing process's feasibility (Hong et al., 2004; Wu \& Hou, 2010).

A logistics outsourcing process with a cost reduction focus (Lieb \& Kendrick, 2003) yields the classical make/buy decision. Because this type of decision lacks a broad perspective, that is, to "see the trees and not the forest" according to Richmond (1993), it is impossible to understand whether the results over time were positive. Moreover, exogenous factors, such as interest rates, transportation and warehousing costs, or logistics supplies may impact the results. Internal factors, such as delays in the outsourcing evaluation process and decision-making, may also influence the end results. According to McCray \& Clark Junior (1999) and Wanke (2004), exposing the relations between internal and external factors, regardless of their controllability, is essential for modeling the logistics outsourcing process. The inclusion of internal and external factors in a system dynamics model encourages considering the system as the cause and the effect of its own behavior. Thus, these factors may help to understand what can influence the logistics outsourcing process positively or negatively.

This article conducts a case study based on a strategic vision to understand the feasibility of a logistics outsourcing process by modeling the latter from its conception until its consolidation at the end of the first contract term with the 3PL provider. Consistent with Rahmandad (2008), complex relationships, delays and feedback processes, all of which are associated with a dependency on one supplier, indicate that systems thinking and the system dynamics method are adequate tools to examine the trade-offs and the policies of a logistics outsourcing process.

Hence, this research aims to present a system dynamics model based on Forrester's seminal work (1971) by considering trust relationships (Kim et al., 2008; Luna-Reyes et al., 2008) and other important factors in the several phases or steps of the logistics outsourcing process, namely, information leakage and employee morale, operational monitoring, and the 3PL employee learning process. This type of model will help to maximize the positive economic results of the outsourcing process for the contracting company.

\section{Literature review}

\subsection{Economic theory and logistics outsourcing}

According to Vivaldini et al. (2012) logistics outsourcing from its simplest form to the most sophisticated, as with any other acquisition of logistics services, is a complex activity because it is the purchase of a process; however, it is very different from the purchase of goods or parts of products and components. There are many important studies that describe outsourcing (Vernalha \& Pires, 2005; Paiva \& Souza, 2012) or logistics outsourcing processes (costs, causes, failures, decision-making, attributes, etc.) (Wanke, 2004; Bandeira et al., 2012; Maloni \& Carter, 2006)

Besanko et al. (2000) describe how many companies consider outsourcing their manufacturing, transportation and warehousing activities because they believe that their partners are more efficient than they are and are in a position to contribute to the needs of several companies to achieve economies of scope and scale and to develop a level of service competence to reduce their transaction and switching costs.

According to Rindfleisch \& Heide (1997), transaction cost analysis models the firm as a governance structure, and Coase (1937) described that the firms and markets are alternative governance structures that differ in their transaction costs. Specifically, it was proposed that, under certain conditions, the costs of economical exchanges in a market may exceed the costs of organizing this exchange inside the company. In this context, the transaction costs are the costs to make the system work and include the ex-ante (e.g., to write and negotiate contracts) and the ex-post costs (e.g., supplier monitoring) as were argued by Rindfleisch \& Heide (1997). According to Lambert \& Emmelhainz (1999), the contracts are long term, and their costs of monitoring should be considered.

Switching costs, in contrast, are based on the economic perspective of the costs of the decision of changing a product or service with the adoption of a new option (Valletti, 2000). For some products or services, substantial costs are incurred when there is a change of supplier. The higher the costs, the higher 
the lock-in effect on the contracting company with the supplier, product or service (Besanko et al., 2000).

Many switching costs have been proposed in the available literature (Klemperer, 1987; Valletti, 2000), including transaction costs required to change suppliers (Elzinga \& Mills, 1998), learning costs, know-how costs and employee morale costs (Chaudhury et al., 1995; Lieb \& Kendrick, 2003). In this last case, low employee morale during an outsourcing process may cause a radical productivity reduction (Bragg, 1998) and even cause internal thefts, both of which are important for this study.

\subsection{A methodological approach to the logistics outsourcing decision-making process}

The selection and evaluation of a third-party logistics (3PL) provider in the logistics outsourcing decision-making process has become fairly complex, involving broad functional areas related to internal and external factors. To understand how human decision makers make decisions in a complex, real world settings and to learn how to support those outsourcing processes, particular approaches have been applied. The most applicable approaches for strategic decision-making, representative of our case, can be classified into three categories (Ghiani et al., 2004, p. 19-20). The first category is (a) benchmarking, which consists of comparing the performance of a logistics system to a "best-practice standard". Although this method may be simple, it yields different solutions in different logistics outsourcing cases; therefore, it can be difficult to draw comparisons among company cases. The second category is (b) simulation, which evaluates the behavior of a particular configuration or policy by considering the system dynamics, as we do. This approach is particularly insightful for strategic decision-making in logistics because managers may evaluate their strategies before investing capital in assets and establishing their logistics system. The third and final category is (c) optimization, which refers to the decision-making process that can sometimes be expressed as a mathematical optimization problem (Zhou et al., 2008). Continuous approximation methods can be used whenever the number of customers is so sufficiently high that demand can be modeled as a continuous spatial function. This approximation often yields closed-form solutions and thus must be used as a simple heuristic (Feng et al., 2011). Moreover, approaches based on multicriteria decision-making (Menon et al., 1998), multivariate statistical techniques (Qureshi et al., 2008) and combined methodologies (Bottani \& Rizzi, 2006; Ho et al., 2012; Buyukozkan
\& Cifci, 2012) have been proposed to address the logistics outsourcing problem (i.e., to select or to evaluate a 3PL provider). Chai et al. (2013) provide an extensive list of references related to decision-making techniques. We urge the use of dynamic methods to simulate a real case.

Therefore, system dynamics (SD) as a simulation approach is used in this study because it provides an integrative, organizing structure for complex and dynamic systems (Forrester, 1971). The integrative process of logistics outsourcing creates relevant feedback in terms of flows, thus making SD a well-suited modeling and strategic analysis tool for the logistics outsourcing decision-making process. According to the lceberg Principle of (Kim, 1999), system structures are the forms according to which the parts of systems are organized; therefore, any causal relation between important variables and system factors can be studied (Larsen et al., 1997). This ability to study causal relations is one of the most important gaps in logistics outsourcing studies (McCray $\&$ Clark Junior, 1999). Knowing the dynamics of the logistics outsourcing process, the results show the variations in key performance indicators and indicate whether the financial objectives of the process were reached. These aspects are rarely mentioned in the literature because they involve logistics outsourcing or other types of outsourcing projects (McCray \& Clark Junior, 1999).

Systems dynamics is an approach that uses cognitive and computer simulation tools to understand complex management problems (Pidd, 1996; Capelo $\&$ Dias, 2009). The authors assume that the reader is familiar with most SD mapping tools, but a brief introduction follows. For the model-building step, certain tests suggested in the SD literature were used, such as the behavior reproduction test, the integration and time step integration errors tests and the extreme conditions test (Roberts et al., 1983; Sterman, 2000).

Flow diagrams and causal loop diagrams are used to represent relations and strategy problems (Sterman, 2000), as in our study. Flow diagrams, when combined with causal loop diagrams, allow users to view how various stocks and flows in the system influence each other and how feedback enters the system (Kim, 1999). Figure 1 shows an example of a savings account in a flow diagram format. The double-lined arrow flows out of a cloud, which indicates the limits of the system (source). On the other side, the double-lined arrow ends in a cloud, which indicates the system's other limit. The interest rate is a constant that affects only the net balance of the savings account.

Finally, delays constitute a critical piece of system dynamics (Rahmandad, 2008). They are responsible for 


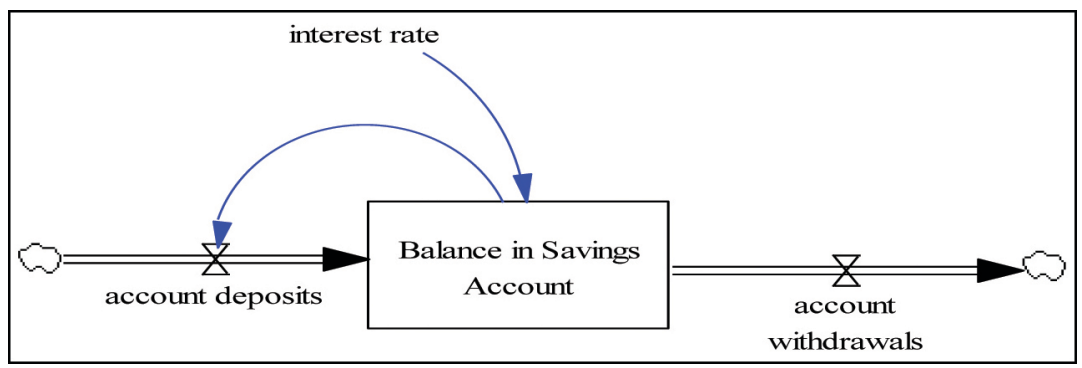

Figure 1. Example of a Flow Diagram. Source: Authors.

generating instability and oscillations in the system (Sterman, 2000). Delays can affect the evolution of cognitive factors (Rahmandad, 2008). An important factor in most types of delays is the time span of the delay or the amount of time that an outflow takes to react to an inflow (Roberts et al., 1983). There are two types of delays: (1) material delays, which capture the physical flow, for example, products moving in a supply chain, and (2) information delays, which represent a gradual adjustment of perceptions or beliefs. All beliefs, expectations, forecasts and projections are based on the information available to the decision maker at a given point in time. Time is required to collect information, and people do not change opinions instantly. Time is also necessary for reflection and emotional change before a new situation is accepted. Information, perceptions and beliefs cannot be preserved; therefore, a different structure from material delays was developed to represent them (Sterman, 2000).

The next section presents the methodology developed based on the problem description and a dynamic problem definition, with the formulation and analysis of a simulation model based on a standard case presented by Larsen et al. (1997) and Roberts et al. (1983).

\section{Methodological aspects}

A revelatory single-case study with a descriptive approach was developed to obtain a deeper understanding of the dynamics of the logistics outsourcing process. The study was based on a large multinational company (fictitiously named Global) that outsourced its physical distribution operations over a period of four years. In this research, a contemporary phenomenon, such as the logistics outsourcing process, was studied in its actual Brazilian dynamic context, and the borders between them were unclear (Yin, 2009; Eisenhardt, 1989). All of the data and information were obtained from documents and were triangulated with interviews with three important stakeholders in the process:
Global's project manager; Global's operations manager, who continued as the 3PL provider's operations manager after the outsourcing process; and the 3PL provider's general manager, who participated in all of the steps of the logistics outsourcing process. The case is also considered revelatory because real data and information on outsourcing projects of this magnitude can rarely be obtained and the process and results analyzed (Yin, 2009).

All of the information is real. However, to maintain the company's confidentiality, specific sales and cost values were changed, but proportions were retained. Global sells consumer product goods (CPGs) and is a market leader in its segment (home and personal care). The Distribution Center (DC) supplies retailers within a radius of approximately $1,000 \mathrm{~km}$ from the DC.

\subsection{Logistics outsourcing phases}

The problem description was developed in the following five phases based on Sinh \& Langley (1997) framework.

1. Process of Identification of the Need to Outsource the Logistics Function: Global's most important international competitor began operations in Brazil. Logistics was among its competitor's key competencies. Global conducted all of the economic and financial evaluations and studied alternatives to improve its logistics. This phase lasted eight months. During this phase, there was a non-official information leakage of the outsourcing project to Global's employees.

2. Process of Evaluating and Selecting the 3PL Provider: Global noted that to secure the required knowledge to pursue the project, they had to invite two international, industry-leading 3PL providers in the CPG sector. This process lasted 10 months. Global expected to reduce its transportation costs by $10 \%$ and its warehousing costs by $25 \%$. Transportation accounted for $70 \%$ of the distribution costs, and warehousing accounted for 30\% of the distribution costs. Both types of costs were responsible for $6 \%$ 
of the total sales. The warehousing costs were composed of $80 \%$ fixed costs and $20 \%$ variable costs.

3. Process of Preparing or Planning for the Implementation of Outsourced Operations: In this step, a detailed project and integration plan was developed. The winning 3PL provider provided a distribution network study and processes review and designed a new DC that was constructed by another party. The hiring and training of personnel also occurred in this step and lasted for 18 months.

4. Process of Implementation or Start-up of Outsourced Operations: This phase lasted for 10 months because of the significant complexity of the outsourced operations.

5. Stabilized Operations (ongoing): Following the 10 initial months of the previous phase, the operation reached stability. The initial contract length was 60 months (five years), a commonly suggested contract period for 3PL providers.

The ex-ante period is the time before the $3 \mathrm{PL}$ provider assumes control over the operations (steps 1 through 3), and the ex-post period is the time after which the 3PL starts operations for its customers (steps 4 and 5).

\subsection{Variables of the dynamic problem}

The problem was characterized based on the following four basic aspects (Roberts et al., 1983):

Perspective: The perspective of this study is that of the outsourcing decision maker in the contracting company (Global).

Time Horizon: The ex-ante period lasted for 36 months, while the ex-post period lasted for 60 months, including 10 months to stabilize operations.

Reference Modes: These modes relate to the problem behavior and how it changes over time. The reference modes are included as operational performance indicators during the outsourcing process and were based on real data on Global's outsourcing process.
Table 1 shows how the indicators (on-time deliveries, inventory differences and returns) change during different outsourcing process periods: at the beginning of the process (to), the time immediately before the 3PL provider assumed operations (t36), the first month of the 3PL provider's operations ( $\mathrm{t} 37$ ) and when stabilization was achieved (t46).

Policy Options: Roberts et al. (1983) show that policy options may be used initially to identify the possible actions to change unwanted system behaviors. It is important to avoid making even minor changes to the model and the causal loops and flow diagrams. The policies suggested were the following:

1. Reduction of the ex-ante period;

2. Operations monitoring during the ex-ante period:

a. Reactive monitoring: only monitor when operations attain a specified minimum level of acceptance;

b. Pro-active monitoring: from the beginning of the outsourcing process, monitor internal operations.

In this context, monitoring entails actions such as increasing the supervision, the auditing and/or the security screening of the following:

- Product shipping and receiving;

- Inventory control;

- Delivery delays; and

- Warehouse, to prevent shrinkage and thefts.

Table 2 shows the other costs that were considered in the model that are related to the transaction costs and the switching costs.

The system's variables, parameters and components collected from interviews with the key informants were displayed through the phases of the logistics outsourcing process as indicated in Figure 2. This figure clearly shows in which phase each variable, parameter and component are important and when their influence begins and ends.

Table 1. Operational indicators at four different moments of the outsourcing process.

\begin{tabular}{|c|c|c|c|c|}
\hline & $\begin{array}{l}(\%) \text { Beginning of the } \\
\text { Outsourcing Process }\left(\mathrm{t}_{0}\right)\end{array}$ & $\begin{array}{c}(\%) \text { Before 3PL Takes } \\
\text { Over Operations }\left(\mathrm{t}_{36}\right)\end{array}$ & $\begin{array}{l}(\%) 3 P L \text { Operation } \\
\text { Start-up }\left(\mathrm{t}_{37}\right)\end{array}$ & $\begin{array}{c}(\%) \text { Time 3PL Stabilized } \\
\text { Operations }\left(\mathrm{t}_{46}\right)\end{array}$ \\
\hline $\begin{array}{l}\text { On-time Deliveries / } \\
\text { month (of Sales) }\end{array}$ & 95 & 80 & 60 & 95 \\
\hline $\begin{array}{l}\text { Inventory Differences/ } \\
\text { year (of average } \\
\text { inventory) }\end{array}$ & 1 & 4 & 0.02 & 0.02 \\
\hline $\begin{array}{l}\text { Returns/month (of } \\
\text { sales) }\end{array}$ & 3 & 4 & 5 & 2 \\
\hline
\end{tabular}

Source: Authors. 


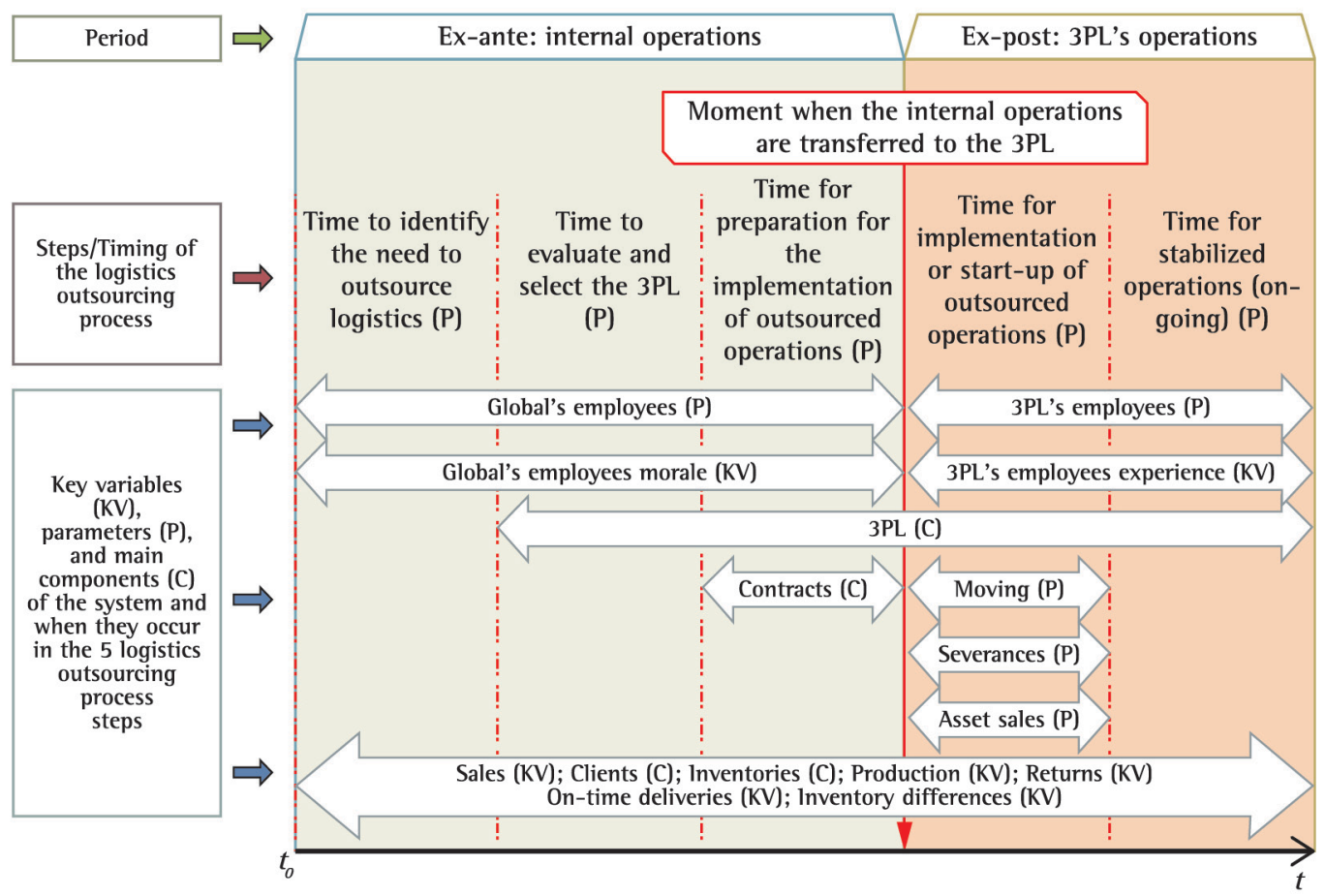

Figure 2. Global's main logistics outsourcing system's Components (C), Parameters (P) and Key Variables (KV). Source: Authors.

Table 2. Additional transaction and switching costs considered.

\begin{tabular}{lc}
\hline \multicolumn{1}{c}{ Cost Description * } & Estimated Values (\$) \\
\hline Moving Costs & $280,000.00$ \\
Severance Payments & $850,000.00^{1}$ \\
Monitoring Costs & $13,500.00^{2}$ \\
\hline
\end{tabular}

Source: Authors. *These costs were considered to calculate the NPV. 'Estimated value for 150 Full Time Employees (FTEs). ${ }^{2}$ Estimated cost per month.

Using SD and the simulation software program VENSIM, the pertinent iterations between all the system's variables and factors were considered. Although models are simplified representations of reality with an objective in mind and with logistics outsourcing being a highly complex process, this model will develop an understanding of the behavior of a real system and, in this way, will provide information about the complex relations within that system. The use of the simulation software is justified because this study aims to analyze a problem that is not a programming problem. Following Sterman (2000), this software was also used because it is free and easy to access.

\section{Formulation of the Simulation Model}

Causal loop diagrams and/or flow diagrams must be developed to build the simulation model.

\subsection{Causal loop diagrams}

The flow diagrams in Figure 3 show the basic financial structure of the developed model. The cash flow for the operation's costs before the outsourcing, the switching costs, the costs with the 3PL operations and the possible income from the sales of assets were compared to the costs of the operation with no outsourcing. The latter constitutes the baseline for the study. Subtracting from the baseline the actual cost of the logistics outsourcing process generated a net cash flow that included a net present value (NPV) that was determined using the weighted average cost of capital (WACC) provided by Global.

Furthermore, it is important that the process be initially defined as two phases: the first phase is the ex-ante phase, which occurs before the operations commence with the 3PL provider, and the second phase is ex-post phase, which occurs after the 3PL provider's operations begin. This structure is necessary because certain important components are in the first phase but not in the second phase and vice versa. Additionally, a number of components transition between both phases. In the first phase, Global's internal process is evaluated with respect to its relationship with its employees and how information leakage influences the logistics outsourcing process results. In the second phase, the interaction of the learning process through training and the acquired operational experience of 
the hired company occur over time, as described by Denrell et al. (2004), to reach operational stabilization in the minimum possible time. The ex-post positive result may be determined more quickly if there is a minimum desirable period for planning the implementation of outsourced operations in the ex-ante period. However, this matter must be carefully treated because the longer the planning period, the worse the ex-ante results are, given the information leakage effect.

$E x$-ante period: It is important to determine the variables and parameters that directly influence the result of the logistics outsourcing project in the latter's initial phases. In this period, Global's employees have an important role in the process but not afterwards in the ex-post period. Information leakage to the employees about the project reduces employee morale, in turn affecting on-time deliveries; the quality of shipments, which causes more returns; and the inventory differences due to either reduced operational quality or internal theft.

It is necessary to understand how changes in returns and on-time deliveries affect sales and to quantify the margin of the lost sales resulting from the logistics outsourcing process. The increase or reduction in sales depends on the time lag for the clients to perceive the reduction or the increase of on-time deliveries or order accuracy. The on-time deliveries, the inventory differences and the returns are influenced by employees' work, which in turn is influenced by the quality of the work of Global's employees and by any of their inadequate actions. If sales and inventory differences are within an expected range, then there will be an acceptable level of trust in the employees' performance that, in turn, increases their morale and provides positive feedback to the process (illustrated in Figure 4).

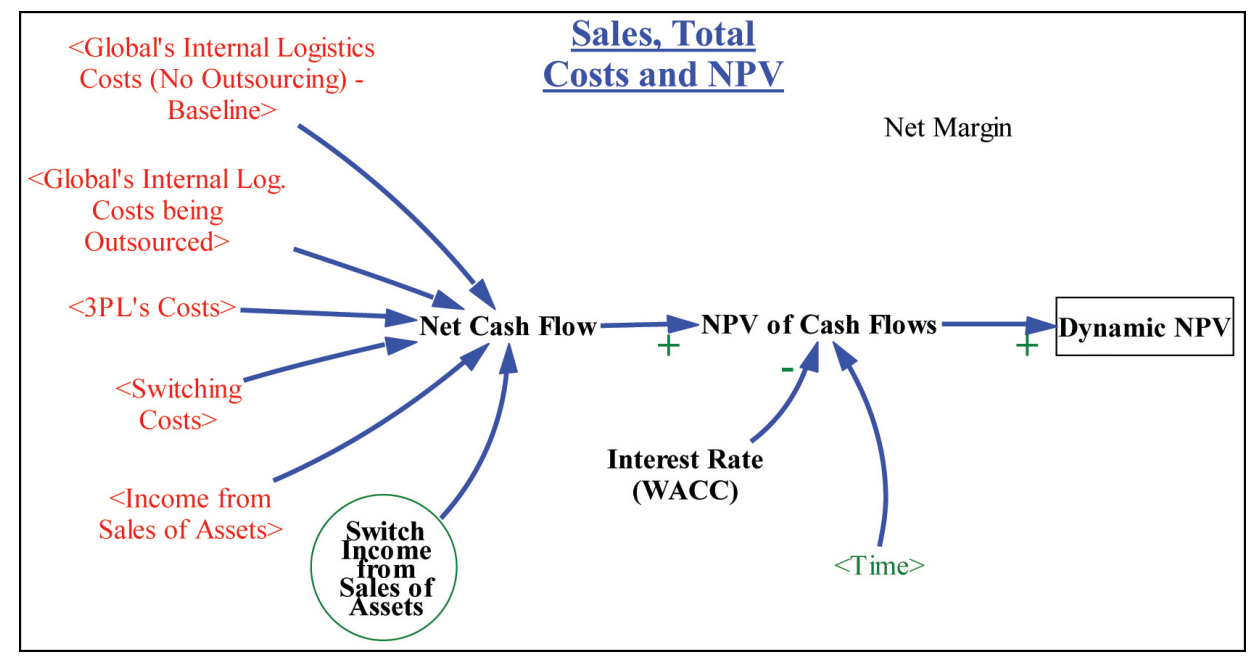

Figure 3. Basic Financial Structure of the Model. Source: Authors.

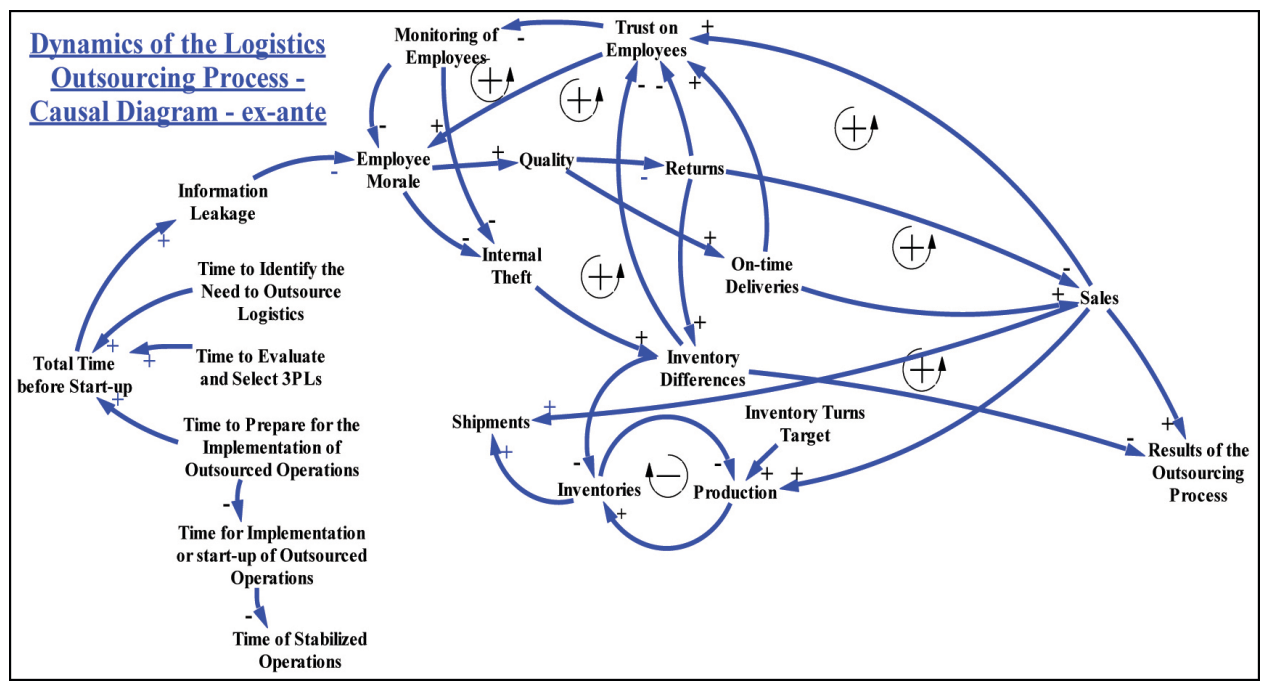

Figure 4. Causal Loop Diagram of the ex-ante period: Logistics outsourcing project. Source: Authors. 
In the case of inventory differences, the company takes time to acknowledge that a problem exists because of administrative processes reporting delays. When Global realizes there is a difference, the company must adjust its inventories and production scheduling to meet adequate inventory coverage or turns. It is assumed in the model that sales are stable and do not exhibit seasonality.

The structure described generated six reinforcing loops and one balancing loop in the causal loop diagram as shown in Figure 4.

For example, if employee morale increases due to increases in trust, there will be increases in quality, on-time deliveries, sales and trust. In this structure, it is important to include a particular item required by the outsourcing process, namely, the information leakage to employees about Global's outsourcing intentions and how these intentions affect employee morale. The information leakage can be observed on the left side of the diagram in Figure 4.

To continue to develop the diagram, it is important to include the time for each phase of the outsourcing process as discussed above. The longer the ex-ante period is, the larger the negative impact of the results of inventory differences, returns and on-time deliveries is. The policy options of the ex-ante period reduction and the ex-ante period employee monitoring were also included.

Ex-post period: This period refers to the time subsequent to the 3PL company beginning operations. During this period, the employees work for the 3PL provider, but the new employees must acquire experience in Global's operations. This process requires time, so the stabilization of operations is delayed.
Global will monitor the 3PL provider in accordance with the literature on transaction costs.

The 3PL provider has objectives in terms of inventory differences $(0.02 \%)$, on-time deliveries $(95 \%)$ and returns (2\%); these objectives were stricter than Global's. The diagram in Figure 5 also shows that if the time to prepare for implementation of the outsourced operations is too brief and does not allow sufficient time to plan and to train future new employees, then the stabilization time will increase. A higher cost subsequently results because the objectives are not achieved within the desired timeframe. Figure 5 shows one balancing feedback loop that is caused by sales variation and production as well as inventory balancing towards the target for inventory turns.

Switching Costs and Asset Sales Revenues: Next, it is important to consider the two other aspects directly related to changing from an internal to an outsourced operation. The major switching costs to be considered are the inventory moving costs (from the old warehouses to the new DC) and the severance payments for Global's former employees. These expenses must be considered in the cash flow of the project at the appropriate time.

Although there could be asset sales revenues (old warehouse or equipment sales), in this case, there were no revenues because Global rented the warehouse, and its equipment was old and depreciated, with approximately null salvage value. Figure 6 shows the complete causal loop diagram for the project. The large sub-processes are enhanced to help the reader understand the diagram's structure. The central section shows Global's basic structure and relates production, inventory, shipments and sales. The top section shows the ex-ante period. The bottom section

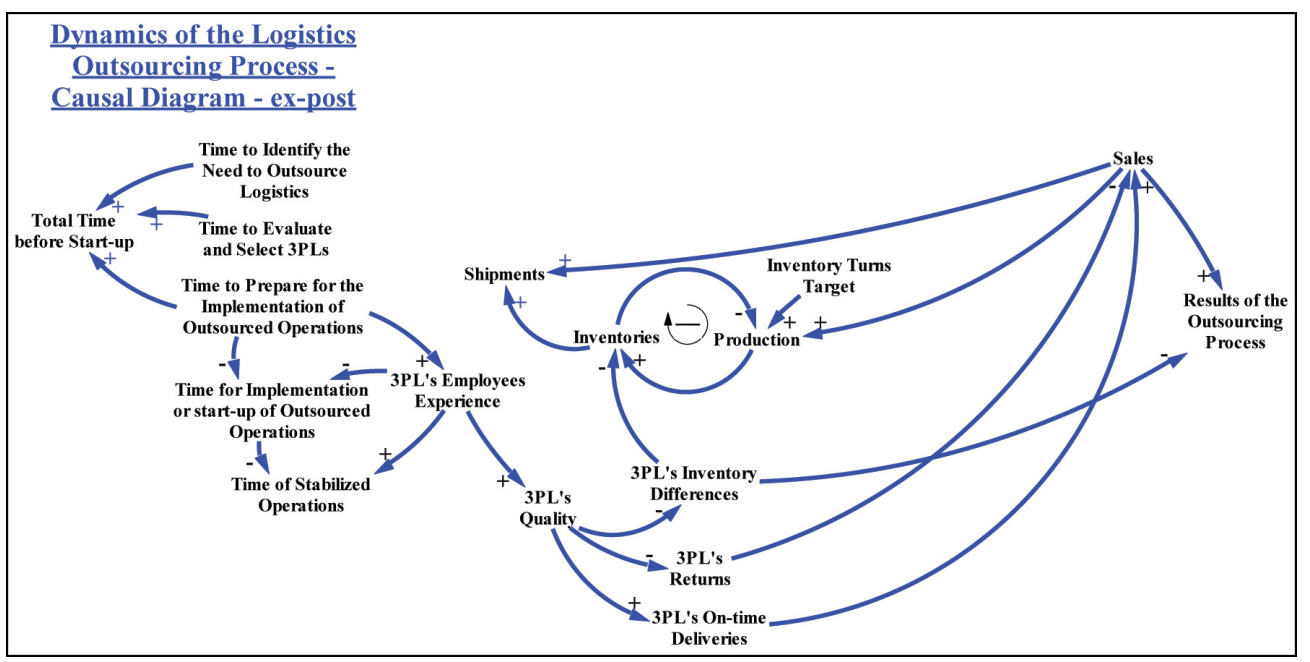

Figure 5. Causal Loop Diagram of the ex-post period of Global's logistics outsourcing project, including experience acquisition by 3PL's employees. Source: Authors. 


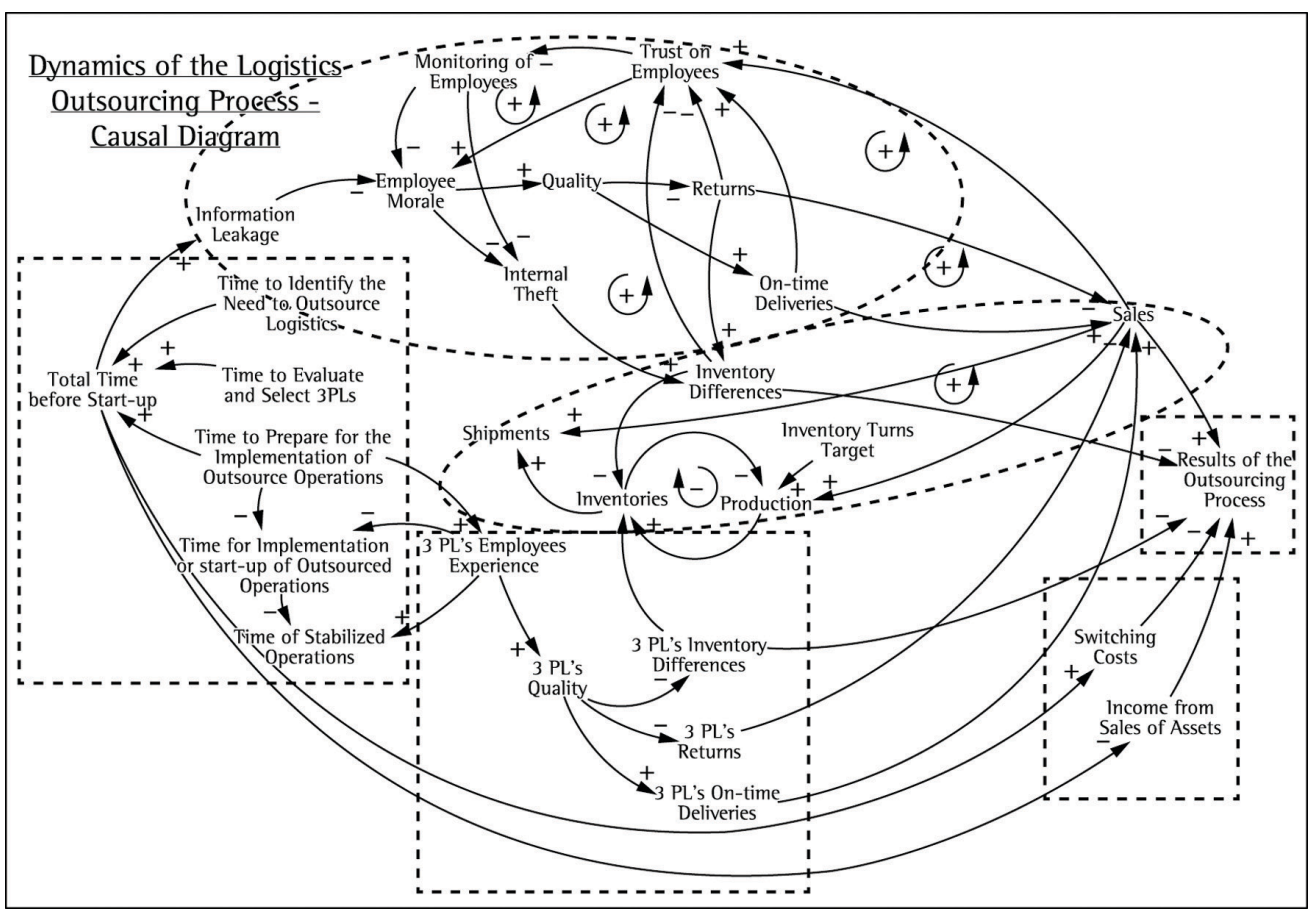

Figure 6. Complete Causal Loop Diagram presenting Global's logistics outsourcing process. Source: Authors.

shows the ex-post period, when the 3PL assumes operations. The left side shows the different project times related to the phases of the outsourcing project. The bottom right side shows the transaction costs and asset revenues, and the middle right side shows the final result, i.e., the cash flow that will be used to calculate the project's NPV.

\subsection{Flow diagrams}

The following flow diagrams, as mentioned in Figure 3, are presented as an evolution of the dynamic model-building process.

\subsubsection{Total cost of Global's internal operations (not yet outsourced)}

Based on the causal loop diagrams, it would be necessary to financially quantify the ex-ante and ex-post operations and the switching costs and revenues from the sales of assets. However, it is also necessary to develop a base case for cost reference purposes of the non-outsourced operations to compare them to the outsourced project's costs and to determine whether the result of the logistics outsourcing process was positive or negative. These costs embrace initial warehousing and transportation costs, inventory differences and return costs, which are costs that refer to the period preceding the start of the logistics outsourcing process (Figure 7). In the case of the inventory, the differences were calculated based on Global's average inventory level.

\subsubsection{Sales, production, inventories and distribution}

The creation of a basic structure for sales, production, inventories and distribution for Global is also important. Sales influence production and shipments. There are sales flows starting in the inventory of products in production, where end-products are taken to inventories and are stocked and subsequently flow at a determined shipping rate to clients (Figure 8).

Sales are determined by inventory differences, returns and the level of on-time deliveries in both periods, before and after outsourcing. Sales variations affect inventories and production. Managerial reports require time to be generated; thus, there is a delayed reaction to adjust production and for the clients to react to a more favorable or less favorable delivery performance from vendors. An internal delay is also included to ship a sales order due to an internal order cycle, which is the time from when the client receives an order from a salesperson or even an electronic data interchange (EDI), which includes consistencies and a credit analysis, until it is physically loaded onto a vehicle for delivery. In this case, a 3-day delay was considered. This value 


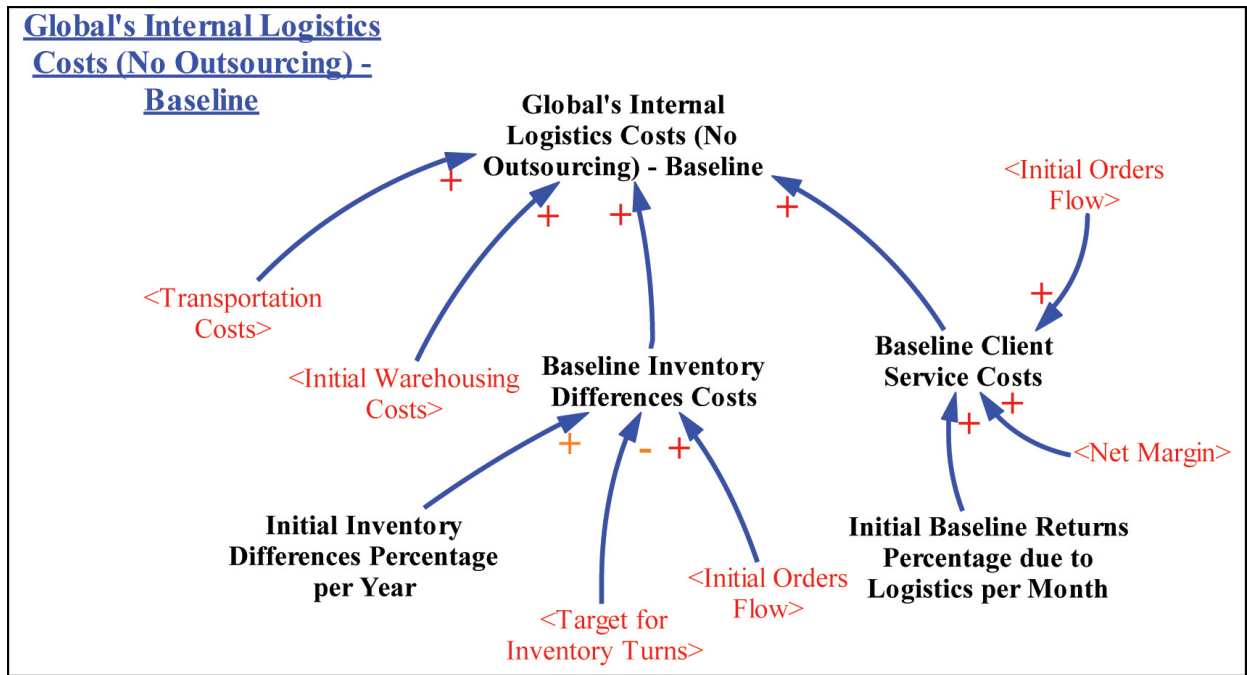

Figure 7. Global's internal operations costs (not yet outsourced). Source: Authors.

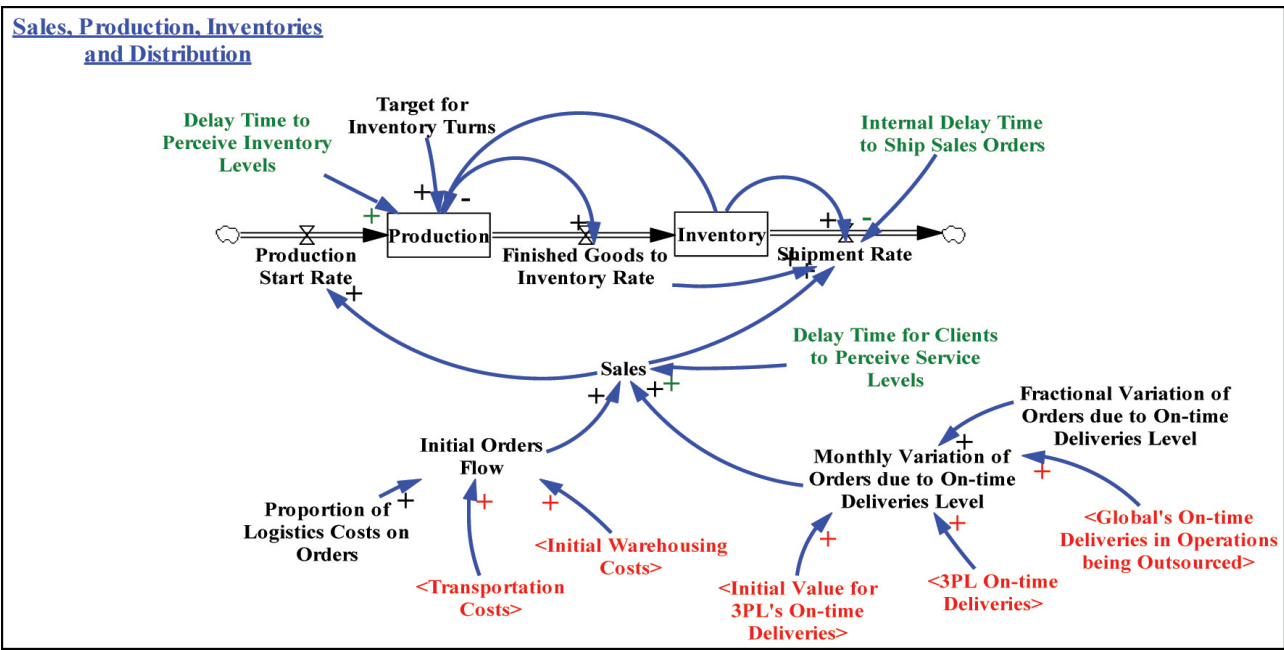

Figure 8. Global's Sales and Distribution Structure. Source: Authors.

is used because Global's internal information flow times and the physical flow of the products are considered. All of the times corresponding for this step were aggregated into a constant in the model, specifically, a sales orders shipment delay.

\subsubsection{Information leakage costs and employee morale}

It is necessary to represent the information leakage and employee morale in the model as shown in Figure 9. Both are represented as stocks that have outflows due to a morale loss caused by the information leakage of the logistics outsourcing process to employees in an informal or formal way, similar to the propagation of an epidemic model (Sterman, 2000).

Thus, each employee contacts other working peers at a specific daily rate. The employees will not necessarily discuss the outsourcing process when they meet because different employees may possess different degrees of knowledge, but it is understood that because it is important news, an employee would likely tell another employee about what is happening. The rate of information propagation would then equal the number of employee contacts multiplied by the probability that the contact would meet another employee who knows the information multiplied by the probability that a knowledgeable employee discusses the outsourcing process. It is assumed that at least one employee receives the 


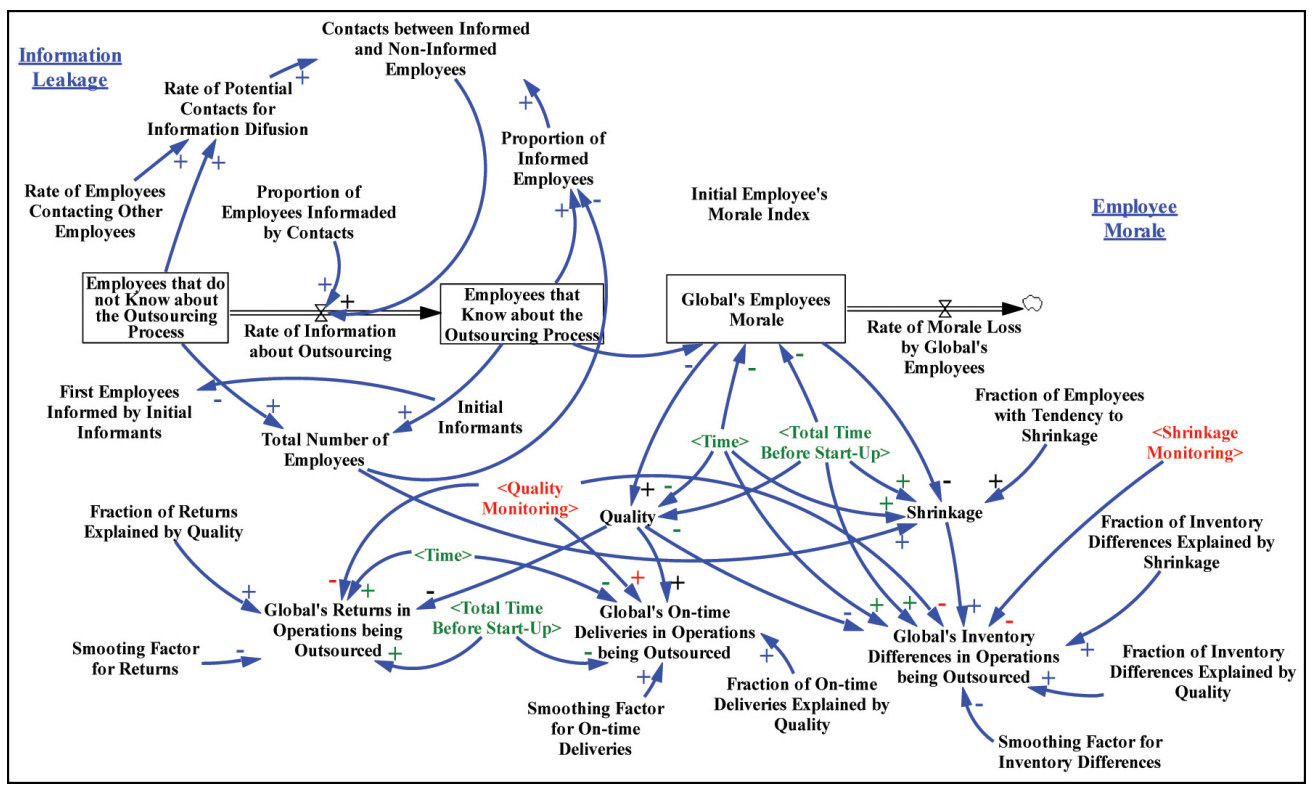

Figure 9. Information Leakage and Employee Morale. Source: Authors.

information, and because he or she contacts other employees who do not know about the logistics outsourcing process, the information is consequently propagated. As employees work together and in shifts, the information transmission process is rapid, and a month is almost enough time for all of the employees to become informed about the logistics outsourcing process.

Information propagation lowers employee morale and thus impacts the overall quality of employees' work, possibly generating less than acceptable employee performance and hence inventory shrinkage and thefts. Inventory differences may be explained partly by the low quality of an employee's work resulting from errors in the quantities shipped or shrinkage and thefts. In turn, more clients receive orders with shortages or overages, thus increasing the number of client returns. The model internally generates its own limitation or adaptations, thus decreasing its service levels because employees will not expose themselves if changes are too drastic.

\subsubsection{The costs of monitoring Global's employees}

Global's monitoring costs (Figure 10) depend on the trust it maintains with its employees. It is believed that because there are operational problems, despite delays in internal managerial reports, the company could react and start monitoring its operations to prevent losses. Employees' trust of the company was represented as a stock that may increase or decrease due to on-time deliveries, returns and inventory differences.
To represent the monitoring starting point, a trustmonitoring trigger was created. In this study, a decrease of 10\% in trust would trigger normal monitoring in a reactive form. At this moment, monitoring starts increasing in terms of the costs and actions that affect job quality and shrinkage. These actions take time to have an effect because they may start with the planning of certain actions and because it could take time until these actions are implemented. These times and delays, which occur before the monitoring action begins yielding positive results, are represented as the time to adjust shrinkage and quality.

\subsubsection{The learning cost of the $3 P L$ provider's employees}

As an important part of 3PL provider's cost structure, in addition to the normal fixed and variable costs that were considered in the model, its employees' learning process will stabilize the operation as shown in Figure 11. The ex-post costs are highly influenced by the process immediately before commencing the outsourced operations or the process of preparing for the implementation of the outsourced operations. If the time is longer than necessary, then there will be unfavorable consequences related to the ex-ante costs. However, if the time is briefer than necessary, then it will take more time than necessary to stabilize operations.

Knowledge is a stock that accumulates learning from training and experience. If the minimum time for preparation before the operational start is fulfilled, then the operations are stabilized in a satisfactory and efficient manner. Previous learning from training is 


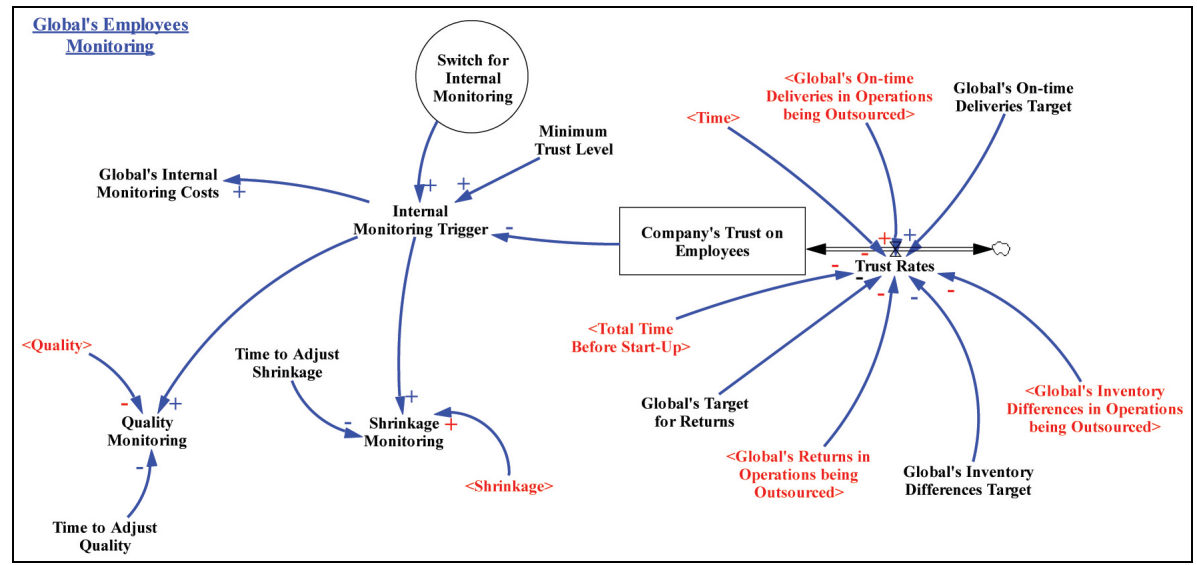

Figure 10. Global's Employee Monitoring. Source: Authors.

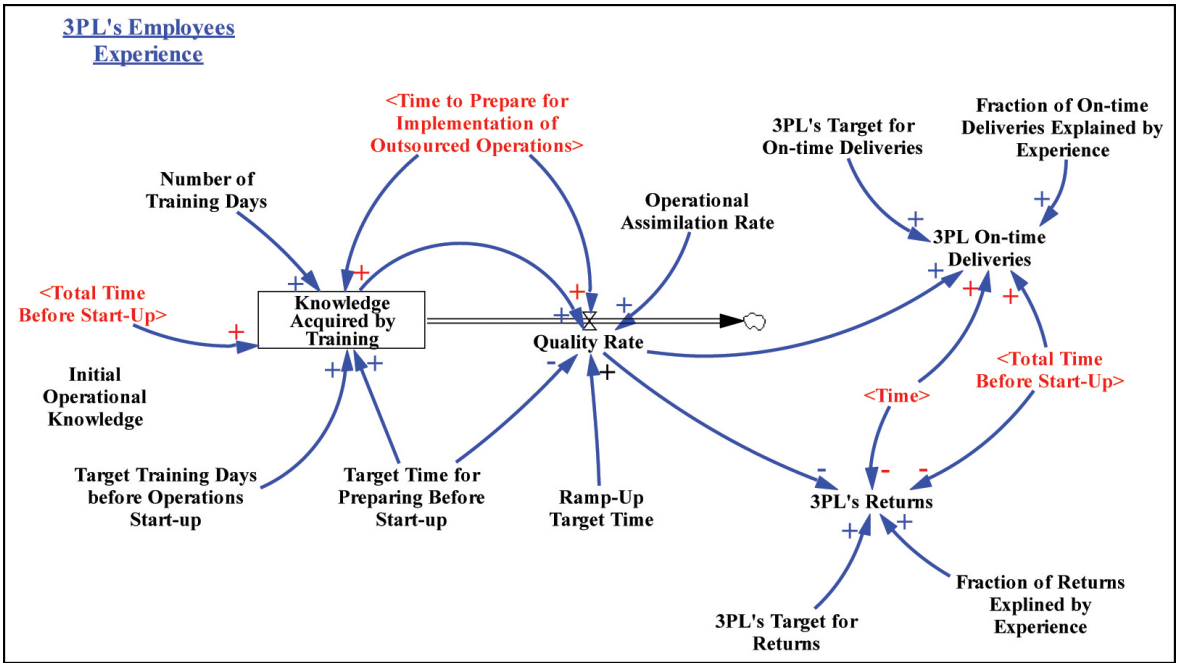

Figure 11. 3PL's Employee Learning. Source: Authors.

applied in the operation and is expanded upon by the employees' experience when on the job such that in practice, their learning also results from successes and failures. This result also affects the inventory differences, returns and the on-time delivery results of the 3PL provider. The inventory differences were not calculated because the 3PL provider has an allowance for inventory differences of $0.2 \%$. Thus, if the difference exceeds this percentage, then Global will charge the 3PL for inventory differences.

\section{Analysis of the model}

The analysis of the model considers all three policies (the reduction of the ex-ante period and the internal monitoring as a reactive or proactive process) for operations implementation, the length of the contract with the 3PL and the interest rate (IRR - internal rate of return based on the WACC).
The model of the final base scenario contains 57 real variables, 60 constants for parameterization and two binary variables. With SyntheSim's functionality and the development of a Control Panel, it is possible to perform continuous simulations of the model's main parameters to evaluate the results nearly instantaneously. The model also allows the user to change the parameters with sliding controls defined from minimum and maximum values; the user can also insert customized graphs of specific variables in the Control Panel. In this study, a graph for the dynamic NPV and a customized graph that shows sales, production, inventories and shipment reactions were included (Figure 12).

The following parameters were included in the Control Panel to evaluate the results of the outsourcing process more efficiently: 
CONTROL PANEL
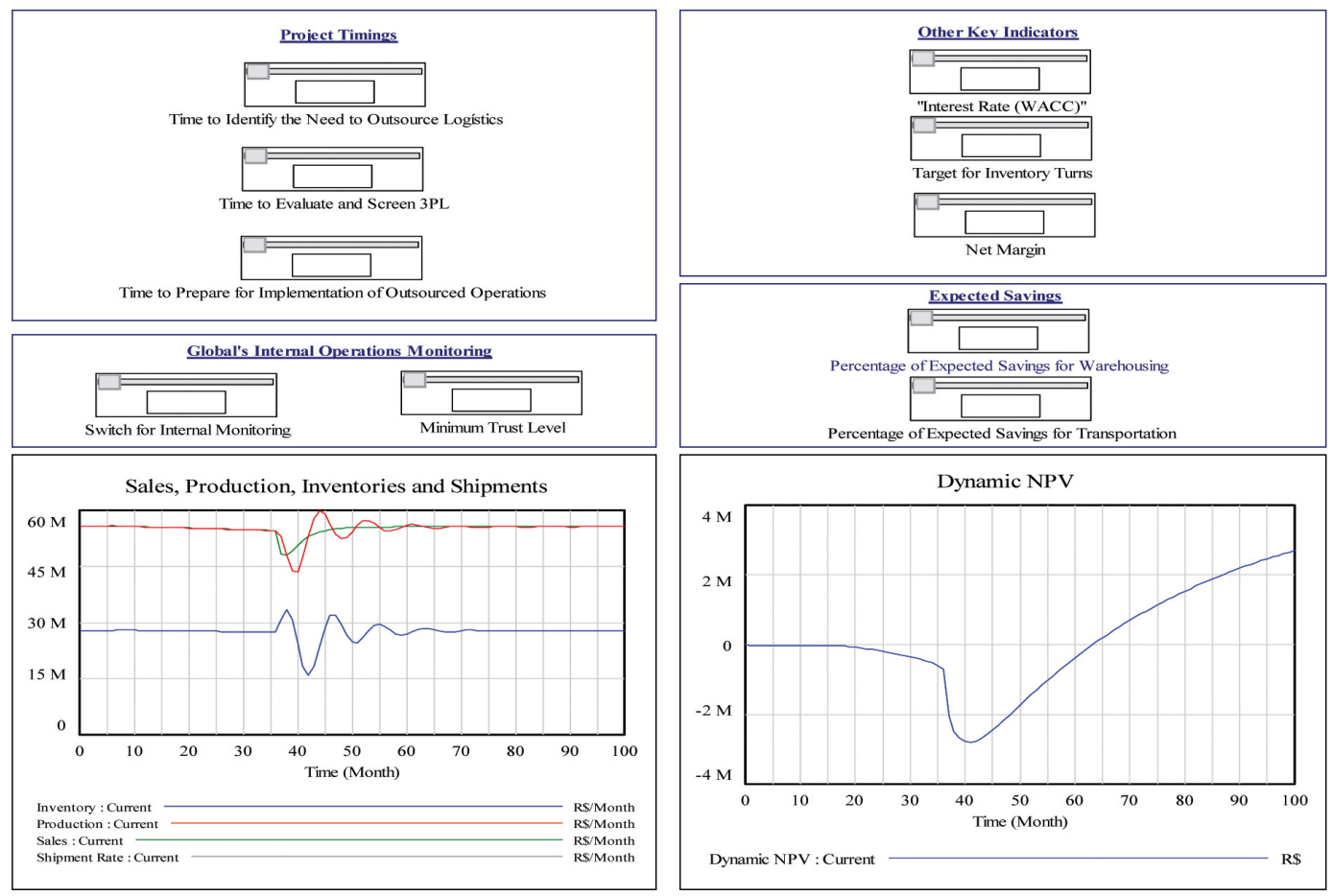

Figure 12. Control Panel with Parameter Sliding Controls and Variable Graphs. Source: Authors.

- Duration of each of the logistics outsourcing phases in months. This duration is considered to be crucial in determining the project's success.

- Interest rate (WACC or internal rate of return): the higher the interest rate is, the smaller the influence of positive future results will be because of the ex-ante losses. The contrary is also true and will predict when the break-even point will occur with respect to changes in the other parameters.

- Target for inventory turns: if higher inventory turns are expected, the lower inventory is retained by Global, thus directly affecting inventory balance differences and sales losses.

- Net Margin: net margins directly influence sales losses resulting from late deliveries and returns.

- Expected Savings (warehousing and transportation): these expected savings will directly influence the project's positive cash-flow results.

- Internal Monitoring Switch: binary variable that, when equal to one, allows the activation of this monitoring either reactively or proactively.

- Minimum Trust Level: represents a minimum percentage of internal acceptance of the deterioration of Global's operational performance indicator results. A 90\% level indicates that a $10 \%$ reduction in the operational results will trigger the internal monitoring process in a reactive form as described above. To generate a proactive internal monitoring process, the trust level must be maintained at 100\%; thus, monitoring will be performed independently of operational results.

\subsection{Policy options}

The first policy suggests a straightforward reduction of the ex-ante period. The second policy advises an ex-ante monitoring of Global's internal operations, thus reducing the impact of the information leakage of the logistics outsourcing project. In this analysis, two monitoring possibilities can be considered: (1) internal ex-ante monitoring results from a reactive process when Global notices reductions in the operational results, thus reducing employee trust and triggering an internal monitoring process and (2) monitoring as a previously defined policy because, once the logistics outsourcing process begins, internal monitoring also begins (proactive ex-ante).

\subsubsection{Reduction of the ex-ante period}

Figure 13 graphically shows an important relation between time and the results of the logistics outsourcing process. From an estimated loss of R\$1,683,290.00 (Brazilian currency) over 36 months, a simple reduction 


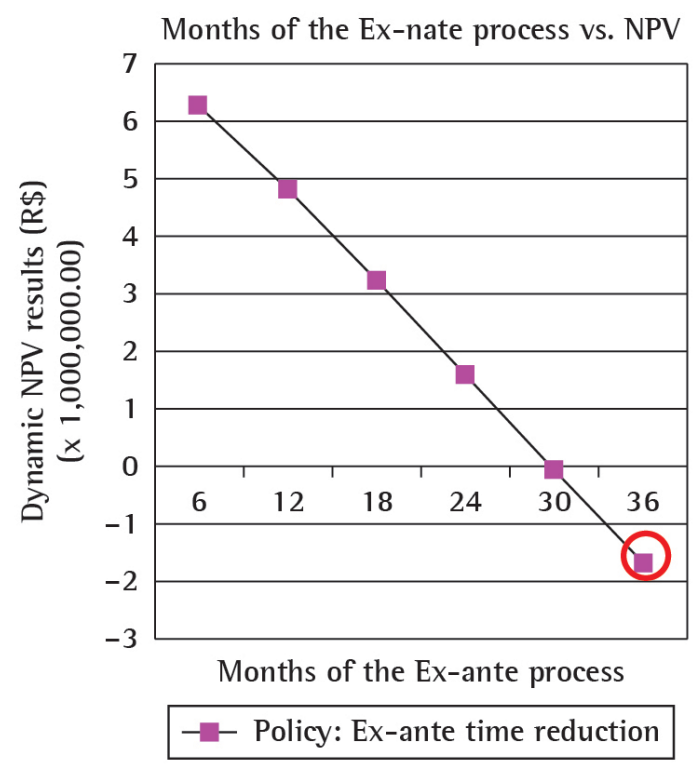

Figure 13. Dynamic NPV Results of the Policy: Reduction of the ex-ante Period. Source: Authors.

of six months from 36 to 30 would reduce Global's actual losses $96 \%$, that is, to $\mathrm{R} \$ 52,345.00$. In other words, during the contract time period of five years, a break-even point would not be attained. Additional reductions of six months to 24 months of the ex-ante period would transform the project's results to a positive $\mathrm{R} \$ 1,602,630.00$.

An additional six-month reduction to 18 months will provide Global with a $102.4 \%$ increase in earnings compared to the 24-month period. In the case of a 12-month ex-ante process, the earnings will increase $48.6 \%$ compared to 18 months, thus equaling $R \$ 4,822,560.00$.

The best scenario would be if the ex-ante period required only 6 months, thus yielding a positive result of R \$ 6,270,550.00; unfortunately, a complete logistics outsourcing process of sufficient quality rarely would be completed within six months.

\subsubsection{Internal Monitoring as a Reactive Process}

Applying internal monitoring as a reactive process facilitates a less negative result in the long ex-ante process (30 months or longer). Alternatively, a greater positive result may be obtained if this process requires less than 30 months. It is important to understand that delays will occur in this type of monitoring because of the time required to generate the information, planning and implementation of stricter supervision, audits and surveillance. These delays prevent previous losses from being recovered during the outsourcing process contract. At the least, it may lower the losses in lengthy ex-ante processes (longer than 30 months). It was observed that when the ex-ante processes lasted for less than 24 months, the contracting company was seldom able to react by strictly monitoring its employees once the level of the operational results failed to reach a point that was considered to be sufficiently critical to require this type of company reaction. The results of the dynamic NPV are similar when comparing the policy of reactive monitoring with the simple reduction of the ex-ante period because the following requirements were insufficient:

- Cause a sufficient loss in the level of trust in the employees to be noticed;

- Trigger internal monitoring;

- Provide sufficient time for the company to implement this type of monitoring.

\subsubsection{Internal monitoring as a proactive process}

For internal monitoring to occur proactively, the company must be aware that problems with the outsourcing process may arise and should take the initiative to monitor the operation starting in the first phase of the process. This result is the most positive compared with other policies tested and is sufficiently effective to be implemented alone. Importantly, because this problem generates a positive result over a 36-month ex-ante period, this policy option is sufficiently powerful to influence the results of logistics outsourcing processes. In Global's case, with an ex-ante period of 36 months, earnings of $\mathrm{R} \$ 2,511,650.00$ are generated. A reduction of six months in the ex-ante process would increase earnings by $29.2 \%$ to $R \$ 3,243,880.00$. Similarly, the earnings increase with each reduction in the ex-ante period as shown in Table 3.

The break-even point is achieved if the ex-ante period is reduced to 30 months alongside a proactive internal monitoring policy in the $24^{\text {th }}$ month of operation. This point implies two important conclusions. The first is that the proactive monitoring process accelerates the process of attaining the break-even point, allowing ex-ante processes that must be longer than 24 months to obtain positive results. The second conclusion is that the period to reach this break-even point is the time that should define the minimum length required for the contract with the 3PL provider (in this case, it should not be less than 24 months). For an ex-ante period of 12 months, it was perceived that although the results were only 
Table 3. Policy simulation results.

\begin{tabular}{cccc}
\hline & POLICY 1 - Ex-ante Time Reduction (\$) & POLICY 1 - Ex-ante Time Reduction (\$) & POLICY 1 - Ex-ante Time Reduction (\$) \\
\hline 36 & $-1,683,290.00$ & $-271,507.00$ & $2,511,650.00$ \\
30 & $-52,345.00$ & $464,125.00$ & $3,243,880.00$ \\
24 & $1,602,630.00$ & $1,602,630.00$ & $3,998,190.00$ \\
18 & $3,244,330.00$ & $3,244,330.00$ & $4,771,080.00$ \\
12 & $4,822,560.00$ & $4,822,560.00$ & $5,560,330.00$ \\
6 & $6,270,550.00$ & $6,270,550.00$ & $6,422,620.00$ \\
\hline
\end{tabular}

Source: Authors.

$15.3 \%$ better than those of the other policies, the use of this policy should also be desirable in the logistics outsourcing process.

Figure 14 compares the results of the two policy options. The red circle shows the actual results of Global's logistics outsourcing process. Both policy options, the reduction of the ex-ante period and proactive monitoring, are superior to the real process that occurred.

Table 3 shows that the briefer the ex-ante period is, the smaller the difference is between the three policy alternatives until six months, when the differences between the three options is approximately null $(2.4 \%)$. The columns refer to the three policies modeled: (1) the reduction of the ex-ante period, (2) the reactive monitoring of internal operations and (3) the proactive monitoring of internal operations.

The baseline results for the 36-month-long ex-ante period show a loss of $R \$ 1,683,290.00$ (shown in row 2 and column 2). In the case of Policy 1 (the reduction of the ex-ante period), the model showed that the time reduction policy is crucial for obtaining a positive result. Compressing this time would transform a loss of $\mathrm{R} \$ 1,683,290.00$ into a profit of greater than $\mathrm{R} \$ 6$ million (with a total ex-ante period of only six months). In the case of Policy 2, when analyzed with an ex-ante period of 36 months, there was a reduction in losses from $R \$ 1,683,290.00$ to $R \$ 271,507.00$ or an approximately $83.9 \%$ reduction compared to Global's real process. This policy could only generate profits if implemented with Policy 1 , which generated a reduction from 36 to 30 months in the ex-ante period ( $R \$ 464,125.00)$. If this period were reduced by an additional six months to 24 months, this policy would not yield additional benefits. This result occurs because the delays in reaction inside Global in terms of operational monitoring were longer than the ex-ante period and could not take effect before the 3PL assumed control of the operations. With an additional reduction of six months, thereby reducing the ex-ante process to 18 months (hence, six months per phase), Global would experience another increase in earnings of $102.4 \%$ compared to the 24-month process, thus indicating that a reduction of only six

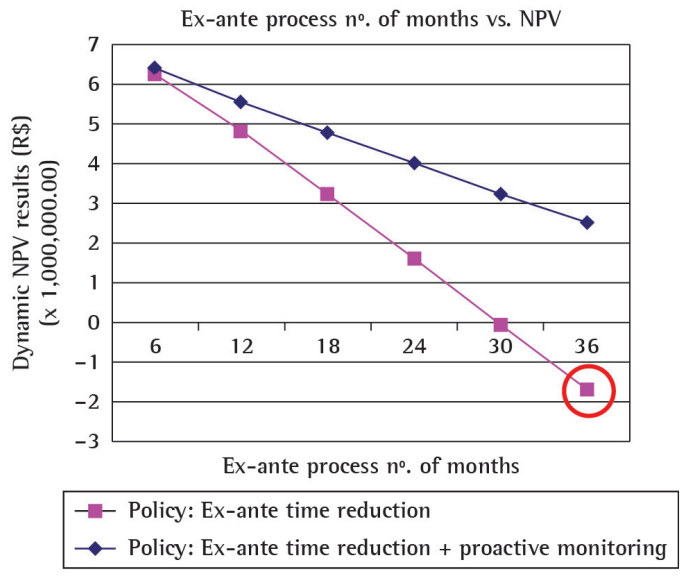

Figure 14. Comparison of both policies: ex-ante and internal proactive monitoring. Source: Authors.

months in this process can double the return on the overall project. An additional six months' reduction, that is, reducing the ex-ante process to 12 months, yields greater earnings, although not as large as the last ex-ante time reduction because, in this case, there is an increase of an additional $48.6 \%$ in total returns, or $\mathrm{R} \$ 4,822,560.00$.

In the case of Policy 3, the results for long ex-ante periods were also favorable, providing positive results over a briefer timeframe, from an ex-ante period of 36 months to six months, and better results for all of the analyzed periods. Thus, this policy is sufficiently powerful and was recommended in all of the logistics outsourcing processes.

\subsection{The length of contracts in logistics outsourcing}

The length of the ex-ante process and the implementation (or lack thereof) of the various policies should influence the lengths of the contracts to be signed with the 3PL provider. If the length is too short, there is the risk that the break-even point would not be achieved. If the length is too long and the conditions are unfavorable, the logistics 
outsourcing process may not produce a positive result. Table 4 shows the number of ex-post months that the model predicts the project will require to attain the break-even point. This time is the minimum reference length of time for the contract, in financial terms, in which the contracting company will not lose money by outsourcing logistics.

On the lines for 30 and 36 months, the recommendation to not outsource is justified by the fact that the break-even point is not attained during the length of time equivalent to the sum of the ex-ante and ex-post periods (considering a five-year contract). The break-even point would be reached only after five years. This result would limit the contracting company's flexibility because it would generate a high transition cost in case the contracting company is no longer interested in continuing with the logistics provider due to contract breaches (transaction costs) that the provider would include in the ex-ante period to guarantee its investments. In all of the cases of ex-ante periods of less than 18 months with the policies of reduction of the ex-ante period and reactive internal monitoring and for all of the ex-ante periods for the proactive monitoring, the break-even point occurs before 36 months. In these cases, contract lengths of three years may be appropriate. In the cases with a 24-month reduction of the ex-ante period and 24 and 30 months of reactive monitoring, the contract lengths should be 5 years to accumulate earnings in the logistics outsourcing process.

\subsection{The Internal Rate of Return (IRR)}

The IRR used for Global's model was 2.5\% per month. This rate is important because it is used to calculate the net present value (NPV) of the project. The model was constructed such that variations in the IRR could be simulated to determine whether there was a difference in the sensibility of the logistics outsourcing process because of periods of economic stabilization or, alternatively, of periods wherein inflation and interest rates were higher. In Figure 15, the NPV results for an example of 72 months (12 months of the ex-ante process plus
60 months of the ex-post process) are shown for variations of the IRR (the comparison includes the $2.5 \%$ per month mentioned).

As shown in Figure 15, if there were no inflation and no cost for obtaining loans, then the return of the logistics outsourcing process would be high. When an IRR of $0 \%$ per month is used, the model yields a result of $R \$ 21,344,200.00$. As the IRR is increased, the project "earnings" rapidly begin to fall because future earnings with the logistics operation are reduced each time the IRR increases, whether by interest rates or inflation, thus making it difficult to overcome the initial transaction and transition costs. It also may be observed that given the model's assumptions, the break-even point would be approximately 5.30\% per month. This exercise allows us to see that Global's logistics outsourcing process with an ex-ante period of 12 months and no monitoring has a greater chance of achieving positive returns in times of greater economic stability, for instance, when the interest rates paid by the company are lower than 85.8\% per annum (5.30\% per month annualized). A reduction of only $1 \%$ in the $\mathrm{IRR}$, from $5 \%$ to $4 \%$

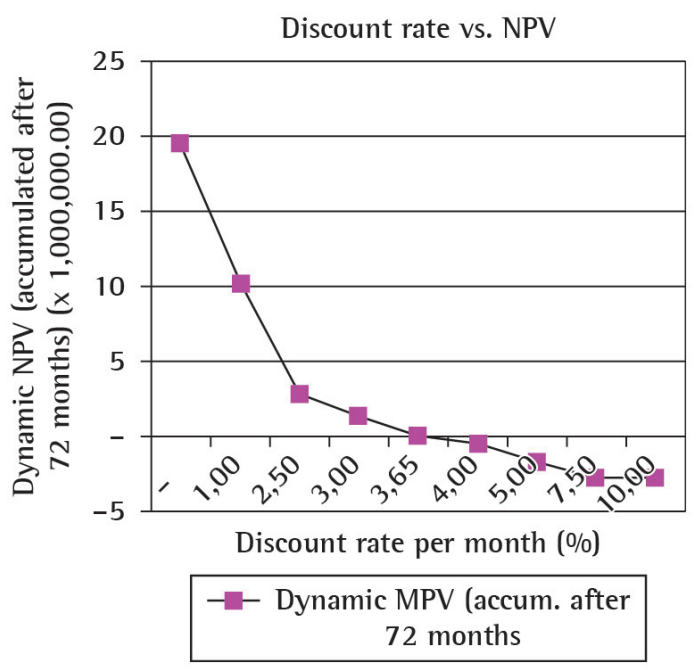

Figure 15. Internal Rate of Return and Dynamic NPV Results. Source: Authors.

Table 4. Considering a 60 Month Contract Length - Time to reach the Break-Even point for the Logistics Outsourcing Project.

\begin{tabular}{|c|c|c|c|c|}
\hline $\begin{array}{l}\text { Ex-Ante Duration } \\
\text { (Months) }\end{array}$ & & $\begin{array}{l}\text { POLICY \# } 1 \text { - Ex-ante } \\
\text { Time Reduction }\end{array}$ & $\begin{array}{l}\text { POLICY \#2 - Ex-ante } \\
\text { Reactive Monitoring }\end{array}$ & $\begin{array}{l}\text { POLICY \# } 3 \text { - Ex-ante } \\
\text { Proactive Monitoring }\end{array}$ \\
\hline 36 & \multirow{6}{*}{$\begin{array}{l}\text { Number of months to } \\
\text { reach break-even point }\end{array}$} & Should not Outsource & Should not Outsource & 28 \\
\hline 30 & & Should not Outsource & 53 & 24 \\
\hline 24 & & 42 & 42 & 24 \\
\hline 18 & & 32 & 32 & 23 \\
\hline 12 & & 26 & 26 & 23 \\
\hline 6 & & 24 & 24 & 23 \\
\hline
\end{tabular}


per month, could make the result approximately six times more positive.

In general, the logistics outsourcing processes are feasible when the economy is in a period of low inflation or when the company is paying low interests in its loans, thus yielding a low weighted average cost of capital (WACC) (less than 5.30\% per month).

\section{Final considerations}

The most important conclusion is that the ex-ante period in the logistics outsourcing process is crucial for determining the financial results of the logistics outsourcing process. The reduction of this period alongside the use of a proactive monitoring policy of internal operations increases the positive results of the contracting company. The length of the ex-ante process and the implementation (or lack thereof) of the mentioned policy options are the considerations that will define the length of the contract to be signed with the logistics provider. If the contract length is too short, then there is a risk that the break-even point of the project will not be achieved. If the length is too long, then the conditions will not be favorable, and the logistics outsourcing project will produce a negative result.

It is considered important to outsource during periods of low inflation and low interest rates in a stable economy and when the contracting company is likewise financially stable. If the contractor is not financially healthy, outsourcing could cause more damage than benefit.

A limitation of the research is that the demand forecasting is considered an endogenous variable, that is, a consequence of Global's real sales. In fact, most companies must forecast their demand to plan their production. A more comprehensive model would be able to simulate the demand forecasting process using different methods. Production planning would also be affected by forecasts, but in this model, this depends on the changes in sales following a target of inventory turns.

Future research could evaluate different levels of outsourcing (whole operations outsourcing vs. manpower-only outsourcing), the earnings as a consequence of collaborative logistics (3PL provider with shared infrastructure vs. dedicated) and the details regarding fixed and variable costs while taking into consideration the scale, complexity and infrastructure (physical and IT) of the operation.

\section{References}

Bandeira, R. A. M., Mello, L. C. B. B., \& Macada, A. C. G. (2012). Elementos de flexibilidade em contratos de terceirização logística: o caso de uma empresa de telecomunicações. Produção, 22(2), 237-248.

Besanko, D. B., Dranove, D., \& Shanley, M. (2000). Economics of strategy. New York: John Wiley \& Sons.

Bottani, E., \& Rizzi, A. (2006). A fuzzy TOPSIS methodology to support outsourcing of logistics services. Supply Chain Management: An International Journal, 11(4), 294-308. http://dx.doi.org/10.1108/13598540610671743.

Bragg, S. M. (1998). Outsourcing: a guide to ... selecting the correct business unit ... negotiating the contract. Maintaining control of the process. New York: John Wiley \& Sons.

Buyukozkan, G., \& Cifci, G. (2012). A novel hybrid MCDM approach based on fuzzy DEMATEL, fuzzy ANP and fuzzy ANP and fuzzy TOPSIS to evaluate green suppliers. Expert Systems with Applications, 39(3), 3000-3011. http://dx.doi. org/10.1016/j.eswa.2011.08.162.

Capelo, C., \& Dias, J. F. (2009). A system dynamics-based simulation experiment for testing mental model and performance effects of using the balanced scorecard. System Dynamics Review, 25(1), 1-34. http://dx.doi. org/10.1002/sdr.413.

Chai, J., Liu, J. N. K., \& Ngai, E. W. T. (2013). Application of decision-making techniques in supplier selection: A systematic review of literatura. Expert Systems with Applications, 40(10), 3872-3885. http://dx.doi.org/10.1016/j.eswa.2012.12.040.

Chaudhury, A., Nam, K., \& Rao, H. R. (1995). Management of Information Systems Outsourcing: A Bidding Perspective. Journal of Management Information Systems, 12(2), 29.

Clark Junior, T. D., \& Jones, M. C. (2008). An experimental analysis of the dynamic structure and behavior of managerial support systems. System Dynamics Review, 24(2), 215-245. http://dx.doi.org/10.1002/sdr.401.

Coase, R. H. (1937). The nature of the firm. Economica, 4(3), 386-405. http://dx.doi.org/10.1111/j.1468-0335.1937. tb00002.x.

Denrell, J., Fang, C., \& Levinthal, D. A. (2004). From T-mazes to labyrinths: learning from model-based feedback. Management Science, 50(10), 1366-1378. http://dx.doi. org/10.1287/mnsc. 1040.0271 .

Eisenhardt, K. M. (1989). Building theories form case study research. Academy of Management Review, 14(4), 532-550.

Elzinga, K. G., \& Mills, D. (1998). Switching Costs in the Wholesale Distribution of Cigarettes. Southern Economic Journal, 65(2), 282-293. http://dx.doi.org/10.2307/1060668.

Feng, B., Fan, Z., \& Li, Y. (2011). A decision method for supplier selection in multiservice outsourcing. International Journal of Production Economics, 132(2), 240-250. http://dx.doi. org/10.1016/j.ijpe.2011.04.014.

Forrester, J. (1971). Principles of systems. Waltham: WrightAllen Press.

Ghiani, G., Laporte, G., \& Musmanno, R. (2004). Introduction to logistics systems planning and control. West Sussex: John Wiley \& Sons. 377 p.

Ho, W., He, T., Lee, C. K. M., \& Emrouznejad, A. (2012). Strategic logistics outsourcing: An integrated QFD and fuzzy AHP approach. Expert Systems with Applications, 39(12), 10841 10850. http://dx.doi.org/10.1016/j.eswa.2012.03.009.

Hong, J., Chin, A. T. H., \& Liu, B. (2004). Firm-specific characteristics and logistics outsourcing by chinese manufacturers. Asia Pacific Journal of Marketing and Logistics, 16(3), 23-36. http://dx.doi.org/10.1108/13555850410765212. 
lañez, M. M., \& Cunha, C. B. (2006). Uma metodologia para a seleção de um provedor de serviços logísticos. Produção. 16(3), 394-412.

Kim, D. J., Ferrin, D. L., \& Rao, H. R. (2008). A trust-based consumer decision-making model in electronic commerce: The role of trust, perceived risk, and their antecedents. Decision Support Systems, 44(2), 544-564. http://dx.doi. org/10.1016/j.dss.2007.07.001.

Kim, H. D. H. (1999). Introduction to systems thinking, innovations in management series. Waltham: Pegasus Communications.

Klemperer, P. (1987). The competitiveness of markets with switching costs. The Rand Journal of Economics, 18(1), 138-150. http://dx.doi.org/10.2307/2555540.

Lambert, D. M., \& Emmelhainz, A. J. T. (1999). Building successful logistics partnerships. Journal of Business Logistics, 20(1), 165-181.

Larsen, E. R., van Ackere, A., \& Warren, K. (1997). The growth of service and the service of growth: Using system dynamics to understand service quality and capital allocation. Decision Support Systems, 19(4), 271-287. http://dx.doi. org/10.1016/S0167-9236(96)00065-6.

Li, S., \& Lin, B. (2006). Accessing information sharing and information quality in supply chain management. Decision Support Systems, 42(3), 1641-1656. http://dx.doi. org/10.1016/j.dss.2006.02.011.

Lieb, R. C., \& Kendrick, S. (2003). The year 2002 survey: CEO perspectives on the current status and future prospects of the third-party logistics industry in the United States. Transportation Journal, 42(3), 5-12.

Luna-Reyes, L. F., Black, L. J., Cresswell, A. M., \& Pardo, T. A. (2008). Knowledge sharing and trust in collaborative requirements analysis. System Dynamics Review, 24(3), 265-297. http://dx.doi.org/10.1002/sdr.404.

Maloni, M. J., \& Carter, C. R. (2006). Opportunities for research in third-party logistics. Transportation Journal, 45(2), 23-38.

Maltz, A. B., \& Ellram, L. E. (1997). Total cost of relationship: an analytical framework for the logistics outsourcing decision. Journal of Business Logistics, 18(1), 45-66.

McCray, G. E., \& Clark Junior, T. D. (1999). Using system dynamics to anticipate the organizational impacts of outsourcing. System Dynamics Review, 15(4), 345-373. http://dx.doi. org/10.1002/(SICl) 1099-1727(199924)15:4<345::AIDSDR177>3.0.C0;2-Z.

Menon, M. K., McGnnis, M. A., \& Ackerman, K.B. (1998). Selection criteria for providers of third-party logistics services: an exploratory study'. Journal of Business Logistics, 19(1), 121-137.

Paiva, J. A., \& Souza, F. M. C. (2012). Modelo de contrato de terceirização de manutenção: uma abordagem principalagente. Produção. 22(4), 796-806.

Peck, H., Payne, A., Chistopher, M., \& Clark, M. (1999). Relationship marketing: strategy and implementation. Oxford: Butterworth-Heinemann.

Pidd, M. (1996). Tools for thinking. New York: Wiley.

Qureshi, M. N., Kumar, D., \& Kumar, P. (2008). An integrated model to identify and classify the key criteria and their role in the assessment of 3PL service providers. Asia Pacific Journal of Marketing and Logistics, 20(2), 227-249. http:// dx.doi.org/10.1108/13555850810864579.
Rahmandad, H. (2008). Effect of delays on complexity of organizational learning. Management Science, 54(7), 1297-1312. http://dx.doi.org/10.1287/mnsc.1080.0870.

Richmond, B. (1993). Systems thinking: critical thinking skills for the 1990s and beyond. System Dynamics Review, $9(2), 113-133$.

Rindfleisch, A., \& Heide, J. B. (1997). Transaction cost analysis: Past, present, and future applications. Journal of Marketing, 61 30-54. http://dx.doi.org/10.2307/1252085.

Roberts, N., Andersen, D., Deal, R., Garet, M., \& Shaffer, W. (1983). Introduction to computer simulation: a system dynamics modeling approach. Reading: Addison-Wesley Publishing Company.

Sinh, H. L., \& Langley, C. J. (1997). A managerial framework for the acquisition of third-party logistics services. Journal of Business Logistics, 18(2), 163-188.

Sterman, J. (2000). Business dynamics: systems thinking and modeling for a complex world. USA: McGraw-Hill Higher Education.

Tsai, W. H., Shaw, M. J., Fan, Y.-W., Liu, K.-C., Lee, K.-C., \& Chen, H.-C. (2011). An empirical investigation of the impacts of internal/external facilitators on the project success of ERP: A structural equation model. Decision Support Systems, 50(2), 480-490. http://dx.doi.org/10.1016/j. dss.2010.11.005.

Valletti, T. M. (2000). Switching Costs in Vertically Integrated Markets. Review of Industrial Organization, 17(4), 395-409. http://dx.doi.org/10.1023/A:1007813411983.

Vernalha, H. B., \& Pires, S. R. 1. (2005). Um modelo de condução do processo de outsourcing e um estudo de caso na indústria de processamento químico. Produção, 15(2), 273-285.

Vivaldini, M., Pires, S. R. 1., \& Souza, F. B. (2012). Improving logistics services through the technology used in fleet management. Journal of Information Systems and Technology Management, 9(3), 541-562.

Wanke, P. (2004). Impactos da sofisticação logística de empresas industriais nas motivações para terceirização. Gestão e Produção, 11(3), 455-467.

Williamson, O. E. (1985). The economic institutions of capitalism: firms, markets, relational contracting. New York: The Free Press.

Wu, Y.-J., \& Hou, J.-L. (2010). An employee performance estimation model for the logistics industry. Decision Support Systems, 48(4), 507-652. http://dx.doi.org/10.1016/j. dss.2009.11.007.

Yin, R. K. (2009). Case study research. design and methods (4th ed., Applied Social Research Methods). Thousand Oaks: Sage Publications.

Yoon, S. W., \& Nof, S. Y. (2010). Demand and capacity sharing decisions and protocols in a collaborative network of enterprises. Decision Support Systems, 49(4), 442-450. http://dx.doi.org/10.1016/j.dss.2010.05.005.

Zhou, G., Min, H., Xu, C., \& Cao, Z. (2008). Evaluating the comparative efficiency of Chinese third-party logistics providers using data envelopment analysis. International Journal of Physical Distribution \& Logistics Management, 38(4), 262-279. http://dx.doi.org/10.1108/09600030810875373. 